\title{
PERAN IBU DENGAN SIKAP REMAJA PUTRI MENGHADAPI MENARCHE
}

\author{
Feni Nur'aini ${ }^{1}$, Susilawati ${ }^{2}$, Nurul Isnaini ${ }^{3}$, Anggraini $^{4}$ \\ 1Program Studi DIV Kebidanan Fakultas Kedokteran Universitas Malahayati \\ Email feninuraini78@gmail.com \\ ${ }^{2}$ Dosen Prodi Kebdanan Universitas Malahayati \\ Email susilawati_samaly@yahoo.com \\ 3Dosen Prodi Kebdanan Universitas Malahayati \\ Email isnaininurul50@yahoo.co.id \\ ${ }^{4}$ Dosen Prodi Kebdanan Universitas Malahayati \\ Email albar_arsenio@yahoo.com
}

\begin{abstract}
Background : Puberty in young women is characterized by the arrival of menstruation for the first time, known as menarche. The response of young women when experiencing menarche varies greatly, there are teenagers who respond positively but the majority who respond negatively. A negative response that generally occurs is anxiety. Rifrianti (2013) states that the majority of girls facing menarche experience anxiety, which is $79.9 \%$, and only $20.1 \%$ of adolescents do not feel anxious.

Objective: the relationship between the role of mothers and the attitudes of the adolencent teen with menarche in SDIT Muhammadiyah Gunung Terang Bandar Lampung.

Methods: This type of quantitative research with cross sectional study approach. The study population of all 4, 5 and 6 grade teenage girls at Gunung Terang Muhammadiyah Elementary School in 2019 totaled 151, a sample of 110 people, a purposive sampling technique. Analysis of univariate and bivariate chi quare test.

Results : obtained mostly stated the role of positive mothers as much as $67(60.9 \%)$ and the majority of young women being positive as many as $69(62.7 \%)$. The statistical test results obtained $p$ value $=0.009(<a$ 0.05).

Conclusion: which means there is a significant relationship between the role of mothers with the attitudes of adolescent teen with menarche at SDIT Muhammadiyah Gunung Terang Bandar Lampung in 2019. It is recommended to mothers / parents to equip adolescents her daughter informed about menarche and the preparations that needed to be made when facing menarche.

Sugestion: Young women in the face of menarche should find a lot of information about menarche both from mothers and from health workers, reliable mass media, teachers in schools and other sources of information. So as not to panic when facing menarche and more confident facing menarche.
\end{abstract}

Keywords: menarche, mother's role, attitude

\section{ABSTRAK}

Latar Belakang : Pubertas pada remaja putri ditandai dengan datangnya menstruasi untuk pertama kalinya yang dikenal dengan istilah menarche. Respon remaja putri saat mengalami menarche sangat bervariasi, terdapat remaja yang berespon positif tetapi mayoritas yang berespon negatif. Respon negatif yang umumnya terjadi adalah kecemasan. Rifrianti (2013), menyatakan bahwa remaja putri yang menghadapi menarche mayoritas mengalami kecemasan yaitu sebanyak $79,9 \%$, dan hanya $20,1 \%$ remaja yang tidak merasa cemas.

Tujuan : diketahui hubungan peran ibu dengan sikap remaja putri menghadapi menarche di SDIT Muhammadiyah Gunung Terang Bandar Lampung.

Metode:Jenis penelitian kuantitatif dengan pendekatan cross sectional study. Populasi penelitian seluruh remaja putri kelas 4, 5 dan 6 di SDIT Muhammadiyah Gunung Terang Tahun 2019 berjumlah 151, sampel sebanyak 110 orang, teknik sampling purposive sampling. Analisa data univariat dan bivariat uji chi quare test.

Hasil:Didapatkan hasil sebagian besar menyatakan peran ibu positif sebanyak $67(60,9 \%)$ dan sebagian besar remaja putri bersikap positif sebanyak 69 (62,7\%). Hasil uji statistik diperoleh nilai $p=0,009(<a 0,05)$.

Kesimpulan : Ada hubungan yang signifikan antara peran ibu dengan sikap remaja putri dalam menghadapi menarche di SDIT Muhammadiyah Gunung Terang Bandar Lampung Tahun 2019. Disarankan 
kepada ibu/orang tua untuk membekali remaja putrinya informasi tentang menarche dan persiapan yang perlu dilakukan saat akan menghadapi menarche.

Saran: Remaja putri dalam menghadapi menarche sebaiknya banyak mencari informasi tentang menarche baik dari ibu maupun dari tenaga kesehatan, media massa yang terpercaya, guru-guru di sekolah dan sumber-sumber informasi lainnya. Agar tidak panik saat menghadapi menarche dan lebih percaya diri menghadapi menarche.

Kata kunci: Menarche, peran ibu, sikap

\section{PENDAHULUAN}

Masa Remaja merupakan salah satu tahap perkembangan dalam rentang kehidupan manusia. Pada tahap ini remaja akan mengalami suatu perkembangan fisik, seksual dan psikososial sebagai ciri dalam masa pubertas. WHO mendefinisikan remaja bila anak telah mencapai umur 12 - 24 tahun. Menurut Depkes RI adalah antara 10 - 19 tahun dan belum kawin. Sedangkan menurut BKKBN adalah $10-19$ tahun (Widiastuti,dkk, 2009).

Pubertas pada remaja putri ditandai dengan datangnya menstruasi untuk pertama kalinya yang dikenal dengan istilah menarche. Respon remaja putri saat mengalami menarche sangat bervariasi, terdapat remaja yang berespon positif tetapi mayoritas yang berespon negatif.

Respon negatif yang umumnya terjadi adalah kecemasan. Hal ini dikarenakan munculnya berbagai bayangan dan ketakutan yang tidak rill, disertai perasaan bersalah atau berdosa yang semuanya dikaitkan dengan proses menstruasi tersebut.

Rifrianti (2013), menyatakan bahwa remaja putri yang menghadapi menarche mayoritas mengalami kecemasan yaitu sebanyak $79,9 \%$, dan hanya $20,1 \%$ remaja yang tidak merasa cemas. Sudjana (2015), menyatakan bahwa hampir seluruh remaja putri yang menghadapi menarche mengalami kecemasan yaitu sebesar 96,5\%, dan hanya $3,4 \%$ remaja yang tidak merasa cemas.

Dampak dari perubahan psikologis mengakibatkan minimnya kemampuan remaja untuk menguasai dan mengontrol emosi. Kondisi ini membuat remaja putri menjadi kurang bertenaga, keengganan bekerja, bosan pada setiap kegiatan yang melibatkan perorangan, kurang bergairah melaksanakan tugas-tugas disekolah yang menyebabkan tidak stabilnya prestasi remaja putri.

Perasaan bingung, gelisah, tidak nyaman selalu menyelimuti perasaan seorang wanita yang mengalami mentruasi untuk pertama kalinya (menarche). Menstruasi pertama atau menarche adalah hal wajar yang pasti di alami oleh setiap wanita normal dan tidak perlu digelisahkan. Namun hal ini akan semakin parah apabila pengetahuan remaja mengenai menstruasi ini sangat kurang dan pendidikan dari orang tua yang kurang. Adanya anggapan orang tua yang salah bahwa hal ini merupakan hal yang tabu untuk di perbincangkan dan menganggap bahwa anak akan tahu dengan sendirinya, menambah rumitnya permasalahan (Proverawati, 2009)

Berbagai gangguan dan kesulitan tersebut secara langsung ataupun tidak langsung dapat mempengaruhi kondisi fisik ataupun psikologis anak. Terlebih lagi bila yang bersangkutan tidak memahami dengan baik apa yang harus dilakukan untuk mengatasi masalah yang terjadi. Kebanyakan dari mereka justru merasa jijik, takut, bingung dan menjadi panik. Dalam situasi seperti ini diperlukan pengetahuan yang benar tentang menarche dan dengan sikap yang positif diharapkan pula orangtua mampu memberikan alternatif pemecahan masalah secara tepat (BKKBN, 2016).

Data demografi menunjukkan bahwa remaja merupakan populasi yang besar dari penduduk dunia. Menurut WHO sekitar seperlima dari penduduk dunia adalah remaja berumur 10-19 tahun. Sekitar 900 juta berada di negara sedang berkembang. Di Asia Tenggara, jumlah remaja mencapai $\pm 18 \%-25 \%$ dari seluruh populasi di daerah tersebut.

Jumlah remaja (penduduk usia 10-24 tahun) di Indonesia saat ini telah mencapai sekitar 66,3 juta jiwa. Ini berarti 1 di antara 4 penduduk adalah remaja (BKKBN, 2016). Hasil Riset Kesehatan Dasar (Riskesdas, 2013), diketahui $37,5 \%$ perempuan Indonesia mengalami menarche pada usia 13-14 tahun; 0,1\% pada usia 6-8 tahun; $19,8 \%$ usia $15-16$ tahun dan 4,5\% pada usia diatas 17 tahun. Usia menarche remaja putri di Indonesia berkisar antara 12-14 tahun. $\mathrm{Di}$ Indonesia didapatkan menarche termuda 9 tahun dan menarche tertua usia 18 tahun dengan nilai ratarata usia menarche terendah terdapat di Yogyakarta (12,5 tahun) dan tertinggi di Kupang (13,86 tahun) (Depkes,2013). Data sekunder di kota Bandar 
Lampung usia menarche pada remaja putri saat ini belum ada.

Dari bagian kesiswaan SDIT Muhammadiyah Gunung Terang Bandar Lampung diperoleh data jumlah siswa kelas IV sebanyak 116 orang, kelas V sebanyak 115 orang, dan kelas VI sebanyak 89 orang. Studi pendahuluan yang dilakukan penulis pada siswi kelas $\mathrm{V}$ di SDIT Muhammadiyah Gunung Terang Bandar Lampung pada akhir bulan April 2019 dengan mewawancarai terhadap 12 siswi didapatkan kesimpulan 9 dari 12 siswa belum mengetahui tentang menarche dan mereka menyatakan tidak tahu apa yang akan dilakukan ketika mengalami menstruasi untuk pertama kalinya, dan 3 dari 12 siswa mengatakan tahu dan bersikap positif karena menganggap menarche adalah hal yang wajar dan pasti terjadi pada setiap wanita.

Berdasarkan latar belakang di atas maka dapat disimpulkan bahwa setiap perempuan pasti akan mengalami menstruasi dan tidak sedikit remaja putri tentunya mengalami sikap kecemasan dan ketakutan ketika menghadapi menarche. Cara menangani hal tersebut berkaitan dengan peran ibu, peran ibu sangat dibutuhkan dalam sikap remaja putri menghadapi menarche, diharapkan peran ibu dapat mengatasi keluhan fisik dan keluhan psikis pada remaja putri. Sehingga peneliti tertarik untuk melakukan penelitian yang berjudul "Hubungan peran ibu dengan sikap remaja Putri menghadapi menarche di SDIT Muhammadiyah Gunung Terang BandarLampung di SDIT Muhammadiyah Gunung Terang Bandar Lampung"

\section{METODE PENELITIAN}

Jenis penelitian kuantitatif dengan pendekatan cross sectional study. Populasi penelitian seluruh remaja putri kelas 4, 5 dan 6 di SDIT Muhammadiyah Gunung Terang Tahun 2019 berjumlah 151, sampel sebanyak 110 orang, teknik sampling purposive sampling, penelitian dilakukan pada bulan Juli 2019, menggunakan kuesioner. Analisa data univariat dan bivariat uji chi quare test.

HASIL

Analisis Univariat

Tabel 1 Distribusi Frekuensi Peran Ibu di SDIT Muhammadiyah Tahun 2019

\begin{tabular}{lcc}
\hline Peran Ibu & $\mathrm{n}$ & Persentase (\%) \\
\hline Negatif & 43 & 39,1 \\
Positif & 67 & 60,9 \\
\hline Total & 110 & 100.0
\end{tabular}

Sumber : Data primer hasil penelitian bulan juli 2019

Berdasarkan tabel 1 menunjukkan bahwa dari 110 responden dapat diketahui bahwa sebagian besar menyatakan peran ibu positif sebanyak $67(60,9 \%)$ responden sedangkan peran ibu negatif sebanyak $43(39,1 \%)$ responden

Tabel 2 Distribusi Frekuensi Sikap Siswa di SDIT Muhammadiyah Tahun 2019

\begin{tabular}{lcc}
\hline Sikap Siswa & $\mathrm{n}$ & Persentase (\%) \\
\hline Negatif & 41 & 37,3 \\
Positif & 69 & 62,7 \\
\hline Total & 110 & 100.0
\end{tabular}

Sumber : Data primer hasil penelitian bulan juli 2019

Berdasarkan tabel 2 menunjukkan bahwa dari 110 responden dapat diketahui bahwa sebagian besar responden menyatakan sikap positif sebanyak $69(62,7 \%)$ responden sedangkan sikap negatif sebanyak $41(37,3 \%)$ responden.

\section{Analisis Bivariat}

Tabel 3 Hubungan Peran Ibu dengan Sikap Remaja Putri Menghadapi Menarche di SDIT Muhammadiyah Tahun 2019

\begin{tabular}{|c|c|c|c|c|c|c|c|c|}
\hline \multirow{3}{*}{ Peran Ibu } & \multicolumn{4}{|c|}{ Sikap Siswa } & \multirow{2}{*}{\multicolumn{2}{|c|}{ Total }} & \multirow{3}{*}{$\begin{array}{c}p \\
\text { value }\end{array}$} & \multirow{3}{*}{$\begin{array}{c}\text { OR } \\
95 \% \mathrm{Cl}\end{array}$} \\
\hline & \multicolumn{2}{|c|}{ Negatif } & \multicolumn{2}{|c|}{ Positif } & & & & \\
\hline & $\mathrm{N}$ & $\%$ & $\mathrm{~N}$ & $\%$ & $\mathrm{~N}$ & $\%$ & & \\
\hline Negatif & 23 & 53,5 & 20 & 46,5 & 43 & 100 & 0,009 & 3,131 \\
\hline Positif & 18 & 26,9 & 49 & 73,1 & 67 & 100 & & $(1,40-7,02)$ \\
\hline Jumlah & 41 & 37,3 & 69 & 62,7 & 110 & 100 & & \\
\hline
\end{tabular}

Sumber : Data primer hasil penelitian bulan juli 2019

Berdasarkan tabel 3 menunjukkan bahwa dari 110 responden, hubungan antara peran ibu dengan sikap remaja putri dalam menghadapi menarche dapat diketahui bahwa dari 69 (62,7\%) siswi yang mempunyai sikap baik ada sebanyak 49 $(73,1 \%)$ siswa yang memiliki ibu yang berperan 
positif. Sedangkan diantara ibu yang berperan negatif, ada $20(46,5 \%)$ siswi yang menunjukkan sikap baik. Hasil uji statistik diperoleh nilai $p=0,009$, karena pv < 0,05 maka dapat disimpulkan ada hubungan signifikan antara peran ibu dengan sikap remaja putri dalam menghadapi menarche di SDIT Muhammadiyah Gunung Terang Bandar Lampung Tahun 2019. Dari hasil analisis diperoleh nilai $\mathrm{OR}=3,131$, artinya peran ibu yang positif mempunyai peluang 3,131 kali membentuk sikap remaja putri yang positif dibandingkan dengan peran ibu yang negatif.

\section{PEMBAHASAN}

\section{Univariat}

\section{Peran lbu}

Hasil analisis univariat menunjukkan bahwa dari 110 responden dapat diketahui bahwa sebagian besar menyatakan peran ibu positif sebanyak $67(60,9 \%)$ responden sedangkan peran ibu negatif sebanyak $43(39,1 \%)$ responden.

Peran merupakan kesadaran yang tumbuh dari dalam untuk berpartisipasi atau ikut serta untuk menyumbangkan segala kemampuan pikir dan fisik demi sebuah kemajuan. Karena itu peran selalu melahirkan kepekaan (sensitivitas) untuk misalnya mengetahui apa yang dirasakan (keluhan dan harapan) orang-orang disekitarnya. Jadi peran bukan sekedar hak dan kewajiban namun lebih merupakan tanggung jawab individual yang terkait dengan harapan dan norma dimana seseorang dituntun kesadarannya untuk memenuhinya sehingga ia menjadi manusia yang bermanfaat bagi sesamanya (Effendi, 2013).

Seorang ibu memiliki peran dalam bentuk tingkah laku yang musti dilakukan seorang ibu terhadap keluarganya seperti merawat suami dan anak-anaknya. Ibu mempunyai peran dan posisi yang penting dan pusat bagi tumbuh kembangan anaknya, khususnya anak perempuannya apalagi dalam hal menstruasi pertamanya. Ibu bisa memberikan informasi sederhana ke anak perempuannya yang akan mengalami menarche, misalnya apa itu menstruasi, seberapa sering menstruasi terjadi, berapa lama menstruasi terjadi, seberapa banyak darah yang keluar dan bagaimana cara menggunakan pembalut, pentingnya menjaga kebersihan dan cara menjaga kebersihan vulva saat menstruasi, apa saja yang tidak boleh dilakukan saat menstruasi, peran ibu penting dalam proses pertumbuhan dan perkembangan anak, terutama pada masa remaja awal. Melalui ibu, remaja mengenal berbagai proses seksual yang terjadi pada tubuhnya.
Pendampingan orang tua, terutama ibu dalam mengawasi masa pubertas anak bertujuan untuk menjaga perilaku menyimpang dan bisa mengarahkan anak-anak yang beranjak remaja dalam menyikapi setiap perubahan semasa pubertas. Disebabkan banyak perilaku remaja yang menyimpang karena belum memahami apa itu pubertas dan bagaimana cara menghadapi dan mengendalikan setiap perubahan dan gejolak yang melanda semua remaja.

Peran ibu dalam menyiapkan menarche pada remaja putrinya dapat dilakukan dengan memberikan pengajaran dan penjelasan pada remaja putrinya terkait menarche seperti apa itu menarche, cara membersihkan darah menstruasi, menjaga diri dari perilaku seksual, organ reproduksi wanita seperti keluarnya darah menstruasi setiap bulan dari dinding rahim ke vagina, cara menggunakan pembalut dengan menempelkan pembalut ke sisi celana dalam tepat di kemaluan, aturan-aturan saat menstruasi seperti anak tidak boleh menjalankan ibadah saat menstruasi dan Menemani, membantu memilih dan membelikan celana dalam haid dan pembalut wanita, apabila remaja putri merasa tidak nyaman dan malu untuk melakukannya dengan sendiri.

Menurut penulis hasil penelitian ini dimana sebagian besar ibu $(60,9 \%)$ telah berperan positif dalam menyiapkan remaja putrinya untuk menghadapi menarche. Peran ibu yang positif dalam memberikan pemahaman menstruasi dan permasalahannya cenderung dapat memberikan persepsi remaja putri yang baik tentang menarche dibandingkan peran ibu yang masih negatif.

\section{Sikap Siswa}

Hasil analisis univariat menunjukkan bahwa dari 110 responden dapat diketahui bahwa sebagian besar responden menyatakan sikap positif sebanyak $69(62,7 \%)$ responden sedangkan sikap negatif sebanyak $41(37,3 \%)$ responden.

$$
\text { Menurut Notoatmojo (2014), }
$$
mendefinisikan pengertian sikap dengan sangat sederhana bahwa sikap itu suatu sindrom atau kumpulan gejala dalam merespon stimulus objek. Sehingga sikap itu melibatkan pikiran, perasaan, perhatian, dan gejala kejiwaan lainnya. Menurut Allport (1954) yang dikutip oleh Sarwono dan Meinarno (2009), bahwa sikap merupakan kesiapan mental, yaitu proses yang berlangsung dalam diri seseorang, bersama dengan pengalaman individual masing-masing, mengarahkan dan menentukan respon terhadap berbagai objek dan situasi.

Sikap dipengaruhi oleh beberapa faktor antara lain pengalaman pribadi, pengaruh orang 
lain yang dianggap penting, pengaruh kebudayaan, media massa, lembaga pendidikan dan lembaga agama serta pengaruh faktor emosional (A. Wawan dan Dewi, 2010). Sikap positif siswa dapat ditunjukkan dengan menjadi bangga atau toleran dengan tubuhnya sendiri, mempergunakan dan melindungi tubuh sendiri secara efektif disertai dengan rasa kepuasan personal, percaya diri (Azwar, 2016).

Menurut penulis hasil penelitian ini dimana sebagian besar siswi $(62,7 \%)$ telah bersikap positif dalam menghadapi menarche. pembentukan sikap positif ini dapat terwujud terutama karena pengetahuan, pendidikan/pelatihan disamping adanya pengalaman pribadi, pengaruh, kebudayaan, media massa, dan emosional seseorang. Faktor yang memegang peranan penting dalam perubahan sikap siswi pada penelitian ini adalah reaksi/respon terhadap pengetahuan dan informasi yang diterima remaja. Remaja yang mendapat informasi yang benar tentang menstruasi maka mereka akan mampu menerima terjadi menarche dan mampu menerima setiap perubahan yang dialami dengan sikap positif. Sebaliknya remaja yang tidak dibekali pengetahuan tentang menstruasi akan merasa cemas dengan perubahan yang dialami dan cenderung bersikap negatif. Remaja yang kurang memperoleh informasi, akan merasakan pengalaman yang negative.

\section{Bivariat}

Hasil uji statistik diperoleh nilai $p=0,009$, pv $<0,05$ maka dapat disimpulkan ada hubungan signifikan antara peran ibu dengan sikap remaja putri dalam menghadapi menarche di SDIT Muhammadiyah Gunung Terang Bandar Lampung Tahun 2019. Dari hasil analisis diperoleh nilai $\mathrm{OR}=3,131$, artinya peran ibu yang positif mempunyai peluang 3,131 kali membentuk sikap remaja putri yang positif dalam menghadapi menarche dibandingkan dengan peran ibu yang negatif.

Hasil penelitian ini sejalan dengan hasil penelitian dengan desain cross sectional di Iran oleh Sooki Z et. al (2015) yang melakukan studi meta-analisis didasarkan pada artikel berbahasa Inggris yang diterbitkan dari tahun 2000 hingga Februari 2015 di Scopus, PubMed, dan Basis data sains langsung dan pada artikel-artikel Persia di basis data SID, Magiran, dan Iran Medex dengan kata-kata kunci yang ditentukan dan MeSH mereka setara sebanyak 46 artikel yang dipilih berdasarkan kriteria inklusi mendapatkan hasil bahwa dari perspektif gadis remaja di Iran dan negara-negara lain, dalam 56\% kasus, ibu adalah yang sumber informasi terkini tentang proses pubertas, menarche, dan menstruasi. Sumber informasi pilihan tentang proses pubertas, menarche, dan menstruasi adalah ibu dalam semua penelitian sebesar $60 \%$.

Penelitian Marvan ML dan Abolnik MM (2011) dengan desain cross sectinal study pada 405 remaja postmenarcheal di Meksiko, berusia 1215 tahun mendapatkan hasil bahwa meskipun sebagian besar peserta tahu apa yang harus mereka lakukan ketika mereka mengalami menarche mereka, hanya 39\% menyatakan mereka merasakan siap untuk mulai menstruasi dan peserta yang sebelumnya membahas aspek emosional mens dengan ibu mereka lebih mungkin untuk mengklaim mereka merasa siap untuk mulai menstruasi ketika mereka mendapatkan menstruasi pertama (OR 3,45).

Menurut penulis aspek-aspek emosional menstruasi sebelum menarche sangat penting untuk dipersiapkan dan untuk menumbuhkan sikap positif remaja putri terhadap menarche. Informasi tentang pengetahuan biologis dan aspek praktis menstruasi perlu disampaikan oleh seorang ibu kepada remaja putrinya melalui komunikasi yang efektif antara ibu dan remaja putrinya. Pembentukan sikap positif pada remaja dapat juga terwujud terutama karena pengetahuan, pendidikan/pelatihan disamping adanya pengalaman pribadi, pengaruh, kebudayaan, media massa, dan emosional seseorang. Faktor yang memegang peranan penting dalam perubahan sikap siswi pada penelitian ini adalah reaksi/respon terhadap pengetahuan dan informasi yang diterima remaja. Remaja yang mendapat informasi yang benar tentang menstruasi maka mereka akan mampu menerima terjadi menarche dan mampu menerima setiap perubahan yang dialami dengan sikap positif. Sebaliknya remaja yang tidak dibekali pengetahuan tentang menstruasi akan merasa cemas dengan perubahan yang dialami dan cenderung bersikap negatif. Remaja yang kurang memperoleh informasi, akan merasakan pengalaman yang negative.

Penulis juga berpendapat bahwa peran ibu yang positif sangat berpengaruh dalam mempersiapkan remaja putri untuk menghadapi menarche, peran ibu yang positif juga bisa di pengaruhi dari tingkat pendidikan ibu dan pekerjaan ibu. Dengan pendidikan ibu yang tinggi di harapkan ibu mampu memberikan informasi sedini mungkin tentang menarche dan masa pubertas. 


\section{KESIMPULAN}

Berdasarkan hasil penelitian tentang hubungan peran ibu dengan sikap remaja putri menghadapi menarche di SDIT Muhammadiyah Gunung Terang, maka dapat diambil kesimpulan sebagai berikut :Peran ibu dalam mempersiapkan remaja putrinya menghadapi menarche di SDIT Muhammadiyah Gunung Terang tahun 2019 sebagian besar positif sebanyak $67 \quad(60,9 \%)$ sedangkan peran ibu negatif sebanyak $43(39,1 \%)$. Sikap remaja putri dalam menghadapi menarche di SDIT Muhammadiyah Gunung Terang tahun 2019 sebagian besar positif sebanyak $69 \quad(62,7 \%)$ responden sedangkan sikap negatif sebanyak 41 $(37,3 \%)$ responden. Ada hubungan signifikan antara peran ibu dengan sikap remaja putri $(p=0,009)$ dalam menghadapi menarche di SDIT Muhammadiyah Gunung Terang Bandar Lampung Tahun 2019.

\section{SARAN}

Bagi remaja putri di SDIT Muhammadiyah Gunung Terang Bandar Lampung Tahun 2019. Remaja putri dalam menghadapi menarche sebaiknya banyak mencari informasi tentang menarche baik dari ibu maupun dari tenaga kesehatan, media massa yang terpercaya, guruguru di sekolah dan sumber-sumber informasi lainnya. Agar tidak panik saat menghadapi menarche dan lebih percaya diri menghadapi menarche. Bagi Ibu siswi di SDIT Muhammadiyah Gunung Terang Bandar Lampung Tahun 2019. Peran ibu sangat mempengaruhi sikap remaja putri yang akan menghadapi menarche. Diperlukan peran positif dari ibu agar putrinya dalam menghadapi menarche dapat tenang dan tidak berdampak negatif dan mengganggu aktivitas sehari-hari. Sebaiknya ibu membekali informasiinformasi pada remaja putri tentang kesehatan reproduksi dan persiapan yang dilakukan saat akan menghadapi menarche. Bagi lahan penelitian SDIT Muhammadiyah Gunung Terang Bandar Lampung Tahun 2019. Agar lebih meningkatkan pemberian informasi tentang menarche dengan memberikan materi-materi tentang kesehatan reproduksi, sehingga siswi-siswi dapat memahami dan mempersepsikan menarche dengan benar dan tidak berdampak buruk secara psikologis. Bagi peneliti selanjutnya Agar dijadikan bahan pertimbangan untuk melanjutkan penelitian ini faktor yang berpengaruhterhadap sikap remaja putri dalam menghadapi menarche.

\section{DAFTAR PUSTAKA}

Ali,Mohammad dan Asrori, Mohammad.(2009). Psikologi Remaja (Perkembangan Peserta Didik). Jakarta : PT Bumi Aksar

Arikunto. (2014). Prosedur Penelitian Suatu Pendekatan Praktek. Edisi Revisi V. Jakarta : Rineka Cipta.

Asriati. (2018). Hubungan dukungan orang tua dan sikap remaja putri dengan kesiapan menghadapi menarche pada siswa kelas VI di SDN 9 Kota Kendari.

Azwar, S. (2016). Sikap Manusia Teori dan Pengukurannya Edisi ke-2. Yogyakarta: Pustaka Pelajar

Departemen Kesehatan Republik Indonesia (Depkes RI). (2017). InfoDaTIN Pusat Data dan Informasi Kementerian kesehatan RI. Jakarta : Departemen Kesehatan Republik Indonesia.

Efendi, (2013). Peran, Tanggerang : Lotus Books.

Fajri, A dan Khairani, M. (2011). Hubungan Antara Komunikasi Ibu dan Anak dengan Kesiapan Menghadapi Menstruasi Pertama (Menarche) Pada Siwi SMP Muhammadiyah. Banda Aceh. Program Studi Psikologi, Fakultas

Hayuningtyas Devita. (2017). Hubungan peran ibu terhadap sikap remaja putri menghadapi menarche di SDN 01 Taman Kota Madiun. Program Studi IImu Keperawatan STIKES Bakti Husada Mulia Madiun.

Kementerian Kesehatan Republik Indonesia Politeknik Kesehatan Kendari Jurusan Kebidanan Prodi D-IV

M.L. Marvan PhD, M. Molina - Abolnik MA. Mexican Adolescents' Experience of Menarche and Attitudes Towart Menstruation: Role of Communication between Mothers and Daughters

Notoatmodjo. (2018). Metodologi Penelitian Kesehatan. Jakarta : PT. Rineka Cipta. .(2014).

Ilmu Perilaku Kesehatan. Jakarta : Rineka Cipta.

Proverawati dan Misaroh, (2009). Menarche Menstruasi Pertama Penuh Makna. Yogyakarta : Nuha Medika.

Rifrianti Destri. (2013). Tingkat kecemasan siswi kelasVII dalam menghadapi menarche di SMP Warga Surakarta. Program Studi Diploma III Kebidanan Sekolah Tinggi IImu Kesehatan Kusuma Husada Surakarta.Kedokteran Universitas Syiah Kuala Banda Aceh. 
Riskesdas. Riset Kesehatan Dasar. Laporan Nasional. (2013). Badam Penelitian dan Pengembangan Kesehatan Republik Indonesia. Avaible From URL : http :// www.litbang.depkes.go.id / Laporan RKD / Indonesia Riskesdas.

Silalahi,( 2015). Metode Penelitian Sosial Kuantitatif. Bandung : PT Refika Aditama

Suhardono, (2018). Teori Peran Konsep, Derivasi dan Implikasinya. Jakarta : Gramedia Pustaka Utama.
Suryadibrata, (2016). Psikologi kepribadian. Jakarta : Rajawali Pers

Wawan \& Dewi, (2010). Teori Pengukuran Pengetahuan, Sikap dan Perilaku Manusia. Yogyakarta : Nuha Medika.

Widyastuti, Y,( 2009). Kesehatan Reproduksi. Yogyakarta: Fitrimaya

Zahra sooki, Mohammad Shariati (2016). The Role of Mother in informing Girls About Puberty : Meta Analysis Study 